\title{
Interactive comment on "Implications on atmospheric dynamics and the effect on black carbon transport into the Eurasian Arctic based on the choice of land surface model schemes and reanalysis data in model simulations with WRF" by Carolina Cavazos Guerra et al.
}

Anonymous Referee \#2

Received and published: 22 December 2016

\section{General comment:}

The present study investigates the sensitivity of the WRF model in the western Eurasian Arctic to the choice of land-surface schemes (2 schemes) and to the reanalysis datasets used to set WRF's initial and boundary conditions (2 datasets). WRF results are evaluated against surface and radiosonde observations, and the setup deemed best is used in the WRF-Chem model to simulate black carbon in the Arctic and evaluate model results. Land-surface modeling in the Arctic and Arctic BC are both 
very timely topics, and since WRF and WRF-Chem start being used more and more for Arctic studies, it is also important to investigate quantitatively how well the different setups and input datasets perform in this region. While only 2 reanalysis datasets and 2 land surface schemes are being tested in the present study, I found this choice sensible: on the one hand, ERA-Interim and the Noah-Land surface model are both very commonly used options in WRF/WRF-Chem; on the other hand, ASR is Arctic-specific and NoahMP, contains a relatively detailed snow model, so both elements could be considered as more suited a priori to the Arctic region than the "default" setup. While there are many interesting new results in this study, there are two important issues that I think should be addressed before publication to ACP. The main issue is that the link between the WRF (LSM + reanalysis) and WRF-Chem (BC) parts of the study is not sufficiently developed, although the authors state that one of their objectives is to "to assess the role of the modeled atmospheric circulation in the simulated BC concentrations inside the Arctic domain". In addition, every evaluated setup appears to have some important deficiency, which could have strong impacts on modeled BC concentrations. This influence should be discussed in more detail in the manuscript, at the very least for the chosen setup using NoahMP + ASR. The study would also be much stronger if WRF-Chem simulations were also performed while varying reanalysis datasets and LSM to quantitatively evaluate these impacts. The second issue is that I thought that the study was not always very well structured, and that individual features or events in the simulations were sometimes discussed in too much detail, while missing the bigger picture. I encourage the author to clarify and stress the main objectives of this study, and to focus more on results that support directly these objectives. Specifically, I think the manuscript is often missing intermediate conclusions stressing the main findings of each section, and that some important findings are not discussed in the general conclusion (more details are given in the comments below). If the authors can satisfactorily address the points above and the detailed comments below, I recommend publication to ACP. 
1. P. 1, I. 24: "other features", this should be more specific.

2. P. 2, II. 41-42: "The results with WRF-Chem show a strong dependency of the simuACPD lated $\mathrm{BC}$ concentration on the modeled meteorology and the transport of the pollutants around our domain.". This does not seem to be strongly substantiated by the analysis in this study.

3. P. 3, II.56-58: "Consequently, a 'dome' forms that is characterized by low and constant potential temperatures and isolates the Arctic lower troposphere from the rest of the atmosphere by acting as a barrier (the so-called Arctic front)." This is not exactly right. The Arctic "dome" (as mentioned in Stohl, 2006) describes the surfaces of constant equivalent potential temperatures which rise towards the pole, forming "domes", which, in case of isentropic or quasi-isentropic transport, isolate the Arctic surface from (potentially polluted) air masses from the midlatitudes with much higher potential temperatures (see also Carlson 1981, and Klonecki, et al., 2003). The main characteristic of this feature is that it is rising towards the pole, not that temperatures are "low and constant".

4. P. 3, II. 67-68: "This pattern affects atmospheric circulation by modifying weather patterns in the Arctic and beyond, an effect also referred as the Arctic amplification". The sea-ice albedo feedback is not the only driver of Arctic amplification, which is also related to e.g., snow albedo feedbacks, changes in heat transport, cloud feedbacks and water vapor feedbacks, and increased climate impacts of black carbon (Serreze and Barry, 2011).

5. P. 3, I. 82: "In winter (particularly in January), northern Eurasia is one of the major source regions for the Arctic pollution." You could add an earlier reference here, such as Rahn (1981).

Printer-friendly version

6. P. 3 I. 84: "they can descend into the Arctic middle or upper troposphere creating the Arctic haze (Stohl, 2006)." This should be "contributing to Arctic Haze" instead, since the main source of Arctic Haze is thought to be western Eurasian emissions. 
7. P. 4., II. 106-107: "which may not be suitable for use in the Arctic." Can you provide a reference here?

8. P. 4., II. 105: "However, the quality of a reanalysis may also vary regionally in some variables". Reanalysis are not the only source of initial and lateral boundary for regional models (e.g., analysis, climate model results, idealized profiles) so there is a step missing between this sentence and the previous one. Can you also be more specific about which variables are included in "some variables"?

9. P.5, I. 136-137: "We then investigate the implications of these model biases on the atmospheric circulation influencing concentrations of black carbon". I am not convinced this is sufficiently done in this study, since the relatively good BC agreement at Zeppelin station presented at the end of the article could be due to a number of reasons other than the LSM or the reanalysis. The authors should expand the analysis of the effects of these biases on Arctic BC.

10. P. 5, I. 157: This should be " $1-50 \mathrm{~km}$ ". It is in fact not recommended to use WRF in the $4 \mathrm{~km}-10 \mathrm{~km}$ resolution range, because of uncertainties related to the use of resolved vs. parameterized convection.

11. P. 8, section "Comparison between ERA-interim and ASR reanalysis" and in Figure 1: The use of "Bias" to indicate model to model differences on Figure 1 is confusing, since the discussion on this Figure on p.8 also seems to mention biases relative to observations which are not shown on Figure 1.

12. P. 8, I. 286: "This can be explained by the fact that ASR uses MODIS sea ice data." What sea ice data is used in ERA-Interim?

13. P. 9, II. 296-319: Two relevant WRF-Chem references are missing from this study: Sessions et al., (2011), who to my knowledge first used WRF-Chem to study longrange pollution transport (CO) to the Arctic, and Marelle et al (2015), who studied in detail an aerosol transport event from Europe to the Arctic in April 2008, the same

Printer-friendly version

Discussion paper
Interactive

comment 
event being also discussed in the present study. It is also worthy of note that both of these studies (and other related relatively large scale studies of Arctic pollution using WRF-Chem such as Eckhardt et al., 2015 and Thomas et al., 2013) used the Noah Land Surface Model.

14. P. 10, I.353: Quinn et al., 2007 might be a better reference than Stohl et al., 2013 to describe the observed seasonal cycle of Arctic pollution.

Interactive

comment

15. P.11, Section 2.2.1: It is important to specify here if observations from these surface stations and radiosondes are used to create the ERAI and ASR reanalysis or not.

16. P. 13, II. 454-456 and Figures 3-4: The position of the polar dome actually seems to change very little between winter and summer, and even seems to move south during summer in some panels, which contradicts earlier research (e.g., AMAP, 2006, Figure 4.1). Are you certain of these results? The position of the dome in January in Jiao and Flanner (2016) is located further south than the southernmost points in the present study's WRF domain, which could be a problem if WRF results were used to calculate the position of the dome.

17. P.13, II. 468-487: this section would be better framed by distinguishing the behavior of the PBLH over the open ocean, over the continents and over sea ice. There also seems to be strong differences between Noah and NoahMP over snow covered ground, which is interesting.

18. P.14, section 3.1.2: I think the main findings in this part should be stressed more (e.g. at the end of the subsection). Compared to surface data (based on Table 4) it seems that NoahMP_ECMWF performs better than other WRF simulations, except for temperatures where NOAHMP_ASR performs best. I think it is also worthy of note that, in general, WRF simulations here do not agree as well with surface measurements than the original ASR reanalysis. Is it possible that the same observations are used to drive the reanalysis? 
19. P. 14, II. 529-530: Vertical gradients in wind speed and temperature are important in order to estimate vertical mixing, but are far from being the main factor determining transport pathways in a broader sense. Aliabadi et al. (2016) is also not the ideal reference for this statement, since it only considers stable boundary layers and does not concern pollutant transport directly.

20. P. 15, II. 555-560: I think this section should end with a more detailed conclusion paragraph on the main strengths and weaknesses of the different setups, and that this should also be stressed in the general conclusion. There is a good case to make for using NoahMP-ASR, since ASR performs relatively well on its own (i.e. without WRF) and is specifically designed for the Arctic, while NoahMP is a more detailed LSM than Noah (with more detailed snow physics). However, these reasons need to be more explicit here.

21. P. 15, II. 565-566: There are more recent references that could be used here, e.g. Eckhardt et al. (2015).

22. P. 15, II. 569-570 and following section: This last section is really missing an analysis of the link between the first part of the article (Arctic meteorology) and the second part (Arctic AOD and BC). You should try to include some element of analysis on how the biases of the NoahMP_ASR setup, as evaluated in Section 3.1, could have influenced the aerosol results. The best way to quantitatively study these impacts would be to also include WRF-Chem sensitivity simulations to the choice of reanalysis and LSM.

23. P. 16, I. 573: WRF-Chem aerosol optical properties and calculations of AOD should be described earlier in the manuscript, i.e. in Section 2.1.3.

24. P.16, II. 592-596: Other possible sources of error in July are the overestimation of wet removal processes, and a likely underestimation of the influx of aerosols from the lateral boundary conditions (MOZART4 model). 
25. P.16, II. 594: Are you sure GFED is "more advanced" than FINN? Can you provide reasons why?

26. P. 16, I. 609: To what observations in Russia are you referring to? Figure 10 only shows model results.

27. P. 17, II. 615-617: What is the reason for this $3 \times 3 \times 2$ averaging instead of e.g. linear $3 \mathrm{D}$ interpolation at the station location?

28. P. 17, II. 619-628: Due to the relatively small size of the domain (compared to the scales typically involved in long-range pollution transport to the Arctic), it is also possible that some of this good agreement is due, in part, to the good performance of the MOZART4 model used to constrain the lateral boundary conditions. Have you tried comparing directly the MOZART4 BC to Zeppelin observations to evaluate this? You should also mention here that "BC aerosols originating from [...] East Asia" can only originate from the boundary condition.

29. P. 17, I. 624: How did you identify that these air masses originate from "Europe and East Asia Âż?

30. P. 17, I. 631: "The model clearly overestimates the cases with very low BC concentrations in April and in July". I think this is very interesting, since this might indicate that a specific process is missing or is poorly represented in WRF-chem. Do you have any idea of what could cause this?

31. P. 18, Summary: As mentioned above, it would be useful here to remind some of the main strengths and weaknesses found here for WRF simulations with Noah, NoahMP, ERA-Interim and ASR.

Technical comments:

1. P. 2 , I. 36: Remove the quotes around "best", or be more specific why you chose this setup if it is not the best. 
2. P.3, I. 73: "high pressure replaces the low pressure": I might be wrong, but "replaces" seems a bit hyperbolic.

3. P.3 L.80, and P.8, I. 286: this should be "Northern Europe", not "North Europe"

4. P.4, I.88: I think very few modeling studies investigate "Arctic amplification" specifically, studying "Arctic warming" is a much more common area of interest. I also think that studying physical processes helps better understand Arctic warming, weather or pollution more than the reverse, which seems to be suggested here.

5. P.6, I.193: Use "two" instead of "both".

6. P.7, I. 247: "high-resolution simulations" instead of "high-resolution version", since a given version of PWRF, like WRF, can be run at different resolutions.

7. P. 10, I. 340: This should be "the western Eurasian Arctic region".

8. P. 11, L. 408 and elsewhere in the manuscript: the lack of "long-term" observations would be a problem for long-term climate studies, e.g. analysis of trends, but was it really a concern for the present study?

9. P. 15, II. 546-547: There is in fact a WRF option compatible with YSU PBL, topo_wind, to parameterize this sub-grid topographical drag.

10. PP. 16-17, LL. 600-612: There is something wrong with how this section is organized; Figure 10 should be described before discussing the different sources of high $\mathrm{BC}$ concentrations.

11. P. 18, II. 658-659: this should be rephrased with additional references given. As it is, this sentence makes it appear like evidence for the role of these specific processes was given in this study. In addition, the accurate simulation of Arctic sea ice, in general, is probably more important in order to reproduce past and current observations than "the accurate simulation of the Arctic sea ice decline". The same applies when the same possible reasons are mentioned in the abstract. 
12. P. 18, L. 680: "an underestimation lack of aerosol wet removal", there is something wrong with this sentence.

13. P. 26, Table 2: You should also remind in this table what LSM and reanalysis dataset is used for the WRF-Chem simulation.

References:

Interactive

comment

AMAP, AMAP Assessment 2006: Acidifying Pollutants, Arctic Haze, and Acidification in the Arctic, Technical report, Arctic Monitoring and Assessment Programme (AMAP), Oslo, Norway, 2006.

Carlson, T. N., Speculations on the movement of polluted air to the Arctic, Atmos. Environ., 15, 1473-1477, 1981.

Klonecki, A., Hess, P., Emmons, L., Smith, L., Orlando, J., and Blake, D., Seasonal changes in the transport of pollutants into the Arctic troposphere-model study, Journal of Geophysical Research: Atmospheres, 108(D4), doi: 10.1029/2002JD002199, 8367, 2003.

Marelle, L., Raut, J.-C., Thomas, J. L., Law, K. S., Quennehen, B., Ancellet, G., Pelon, J., Schwarzenboeck, A., and Fast, J. D.: Transport of anthropogenic and biomass burning aerosols from Europe to the Arctic during spring 2008, Atmos. Chem. Phys., 15, 3831-3850, doi:10.5194/acp-15-3831-2015, 2015.

Quinn, P. K., Shaw, G., Andrews, E., Dutton, E. G., Ruoho-Airola, T., and Gong, S. L.: Arctic haze: current trends and knowledge gaps, Tellus B, 59, 99-114, 2007. Rahn, K. A.: Relative importances of North America and Eurasia sources of arctic aerosol, Atmos. Environ., 15, 1447-1455, doi:10.1016/0004-6981(81)90351-6, 1981.

Serreze, M. C. and Barry, R. G., Processes and impacts of Arctic amplification: A research synthesis, Global and Planetary Change, 77(1-2), 85-96, doi: http://dx.doi.org/10.1016/j.gloplacha.2011.03. 004, 2011. 
Sessions, W. R., Fuelberg, H. E., Kahn, R. A., and Winker, D. M.: An investigation of methods for injecting emissions from boreal wildfires using WRF-Chem during ARCTAS, Atmos. Chem. Phys., 11, 5719-5744, doi:10.5194/acp-11-5719-2011, 2011.

Thomas, J. L., Raut, J.-C., Law, K. S., Marelle, L., Ancellet, G., Ravetta, F., Fast, J. D., Pfister, G., Emmons, L. K., Diskin, G. S., Weinheimer, A., Roiger, A., and Schlager, $\mathrm{H}$.: Pollution transport from North America to Greenland during summer 2008, Atmos. Chem. Phys., 13, 3825-3848, doi:10.5194/acp-13-3825- 2013, 2013.

Interactive comment on Atmos. Chem. Phys. Discuss., doi:10.5194/acp-2016-942, 2016. 